UDK 528.14

\title{
ERDVINIŲ KOORDINAČIŲ, NUSTATYTŲ TRILATERACIJOS METODU, TIKSLUMAS
}

\author{
Jonas Skeivalas ${ }^{1}$, Robertas Dargis ${ }^{2}$ \\ ${ }^{1}$ Geodezijos ir kadastro katedra, Vilniaus Gedimino technikos universitetas, \\ Sauletekio al. 11, LT-10223 Vilnius, Lietuva, \\ ${ }^{2} U A B$,Eika“, A. Goštauto g. 40 A, LT-01112 Vilnius, Lietuva, \\ el.paštas: ${ }^{1} J o n a s . S k e i v a l a s @ a p . v t u . l t,{ }^{2}$ robertas@eika.lt
}

Iteikta 200607 15, priimta 20060921

\begin{abstract}
Santrauka. Straipsnyje analizuojamas daugkartine linijine sankirta nustatytų taškų erdvinių koordinačių tikslumas. Tokia linijinès sankirtos metodu nustatytų taškų sistema sudaro trilateracijos tinklą. Erdvinių koordinačių reikšmėms skaičiuoti taikoma išmatuotu linijų ilgių parametrinių lygčių sistema, lygtys linearizuojamos pagal apytikres taškų koordinates. Apytikrių koordinačių reikšmès gali būti nustatomos bet kuriuo metodu. Apytikrių koordinačiu pataisos skaičiuojamos mažiausiujjų kvadratų metodu. Nagrinejjama išmatuotų linijų ilgių bei parametrinių lygčių koeficientų klaidų itaka išlygintujų erdvinių koordinačių tikslumui.
\end{abstract}

Reikšminiai žodžiai: trilateracija, erdvinès koordinatės, mažiausiujų kvadratų metodas.

\section{Ivadas}

Daugkartinès linijinès sankirtos metodu nustatomu taškų erdvinių koordinačių reikšmėms skaičiuoti panaudojami linijų direkciniai kampai bei kampų tarp atitinkamų linijų reikšmès. Kampų reikšmėms skaičiuoti taikomos kampu funkcinès išraiškos išmatuotų linijų ilgiais [1-4]. Tačiau toks skaičiavimų metodas nèra racionalus nei taikomų algoritmu, nei skaičiavimu apimties prasme. Straipsnyje pateikiamas erdviniu koordinačių skaičiavimo metodas taikant išmatuotų liniju ilgių parametrinių lygčių sistemą. Netiesinès parametrinès lygtys linearizuojamos pagal apytikres tašku koordinates, kurių reikšmès gali būti nustatomos bet kuriuo metodu [5-7]. Apytikrių koordinačių pataisos apskaičiuojamos mažiausiuju kvadratų metodu, tiesinių parametrinių lygčių sistemą sprendžiant iteracijomis. Iteracinis procesas baigiamas, kai nustatomų tašku koordinačių tikslumas atitinka priimtaji tikslumą. Pateikiamos formulès, pagal kurias nustatoma apytikrių koordinačių bei parametrinių lygčių koeficientų klaidų itaka išlygintuju koordinačių tikslumui.

\section{Linijinès sankirtos teorinis principas}

Taško erdvinèms koordinatems nustatyti daugkartine linijine sankirta taikysime parametrinių lygčių sistemą (žr. pav.):

$$
\left.\begin{array}{l}
\tilde{S}_{1 i}=\left(\Delta \tilde{x}_{1 i}^{2}+\Delta \tilde{y}_{1 i}^{2}+\Delta \tilde{z}_{1 i}^{2}\right)^{1 / 2} \\
\tilde{S}_{2 i}=\left(\Delta \tilde{x}_{2 i}^{2}+\Delta \tilde{y}_{2 i}^{2}+\Delta \tilde{z}_{2 i}^{2}\right)^{1 / 2} \\
\ldots \\
\tilde{S}_{n i}=\left(\Delta \tilde{x}_{n i}^{2}+\Delta \tilde{y}_{n i}^{2}+\Delta \tilde{z}_{n i}^{2}\right)^{1 / 2}
\end{array}\right\},
$$

čia $\tilde{S}_{n i}-$ išlygintoji $n i$-tosios linijos ilgio reikšmė; $\Delta \tilde{x}_{n i}=\tilde{x}_{i}-x_{n}, \quad \Delta \tilde{y}_{n i}=\tilde{y}_{i}-y_{n}, \quad \Delta z_{n i}=\tilde{z}_{i}-z_{n}-$ atitinkami išlygintieji koordinačių prieaugiai; $x_{n}, y_{n}, z_{n}-$ tikslios bazinių taškų koordinatès.

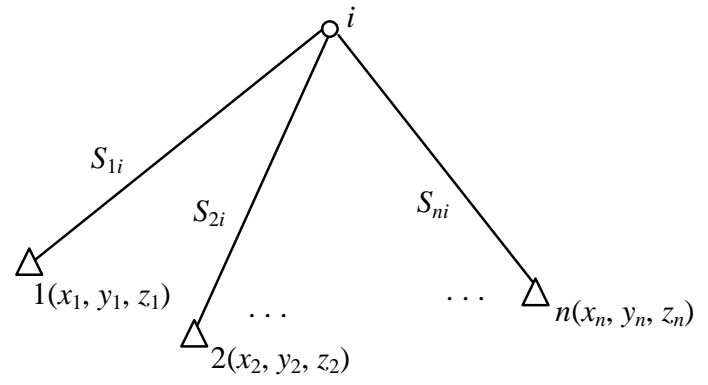

Daugkartinès linijinès sankirtos schema

Schema of multivariant linear intersection

Tikslios bazinių taškų $1,2, \quad \ldots, n$ erdvinès koordinatès gali būti nustatomos ìvairiais metodais, pavyzdžiui, GPS, elektroniniais tacheometrais ir kt.

Parametrinių lygčių sistema linearizuojama $i$-tojo taško apytikrių koordinačių srityje, ir rašoma pataisu lygčių sistema:

$$
\left.\begin{array}{ccc}
v_{1 i}=a_{11} \tau x_{i}+a_{12} \tau y_{i}+a_{13} \tau z_{i}+l_{1 i} \\
v_{2 i}=a_{21} \tau x_{i}+a_{22} \tau y_{i}+a_{23} \tau z_{i}+l_{2 i} \\
\ldots & \ldots & \ldots \\
v_{n i}=a_{n 1} \tau x_{i}+a_{n 2} \tau y_{i}+a_{n 3} \tau z_{i}+l_{n i}
\end{array}\right\},
$$

čia $v_{n i}-n i$-tosios išmatuotos linijos ilgio pataisa, $a_{n 1}=\Delta x_{n i} / S_{n i}, \quad a_{n 2}=\Delta y_{n i} / S_{n i}, \quad a_{n 3}=\Delta z_{n i} / S_{n i}-n i-$ tosios pataisų lygties koeficientai; $\tau x_{i}, \tau y_{i}, \tau z_{i}-i$-tojo 
nustatomo taško apytikrių erdvinių koordinačiu $\left(x_{i 0}, y_{i 0}, z_{i 0}\right) \quad$ pataisos; $\quad l_{n i}=S_{n i, 0}-S_{n i}-n i$-tosios pataisu lygties laisvasis narys, $S_{n i, 0}-$ apytikris $n i$-tosios linijos ilgis, apskaičiuotas pagal apytikres $i$-tojo taško koordinates; $S_{n i}-$ išmatuotas $n i$-tosios linijos ilgis. Apytikrès $i$-tojo taško koordinatès gali būti nustatytos labai apytiksliai, pavyzdžiui, su keleto metrų klaida. Tam gali būti taikomas bet kuris metodas. Linijų ilgiai matuojami elektroniniais tolimačiais.

Parametrinių pataisų lygčių sistema (2) matricu išraiška:

$$
\boldsymbol{V}=\boldsymbol{A} \tau+\boldsymbol{L}
$$

čia $\boldsymbol{V}$ - išmatuotų linijų ilgių pataisų vektorius, $\boldsymbol{A}$ pataisų lygčių koeficientų matrica, kurios matmenys $n \times 3 ; \quad \boldsymbol{\tau}-i$-tojo taško apytikrių koordinačių pataisu vektorius, $\boldsymbol{L}=\boldsymbol{S}_{0}-\boldsymbol{S}$ - laisvujų narių vektorius, $\boldsymbol{S}_{0}-$ apytikrių linijų ilgių vektorius, $S$ - išmatuotų linijų ilgių vektorius.

Taikant daugkartinès erdvinès linijinès sankirtos metodą išmatuotų linijų skaičius turi tenkinti nelygybę $n \geq 3$. Kuo didesnis išmatuotų linijų skaičius, tuo tiksliau galima nustatyti $i$-tojo taško koordinates taikant mažiausiujų kvadratų metodą.

Vektoriaus $\tau$ reikšmė gaunama kaip normalinių lygčių sistemos sprendinys:

$$
\tau=-N^{-1} \omega=-N^{-1} A^{T} P L,
$$

čia $\boldsymbol{N}=\boldsymbol{A}^{T} \boldsymbol{P A}-$ normalinių lygčių koeficientų matrica, $\boldsymbol{P}$ - išmatuotų linijų ilgių svorių matrica, $\boldsymbol{\omega}=\boldsymbol{A}^{T} \boldsymbol{P L}-$ normalinių lygčių laisvujų narių vektorius.

Kadangi $i$-tojo taško pradinès apytikrès koordinatès gali būti nustatytos su didelèmis klaidomis, tai normalinių lygčiu sistema sprendžiama iteraciniu metodu. Vektoriaus $\tau$ reikšmé tikslinama tol, kol dviejų gretimų iteraciju rezultatų skirtumas bus mažesnis už iš anksto pasirinktą teigiamaji skaičių $\varepsilon$, apibūdinantị skaičiavimų tikslumą.

\section{Išlygintųjų koordinačių tikslumo įvertinimas}

Išlygintuju $i$-tojo taško koordinačių reikšmès skaičiuojamos taip:

$$
\left(\begin{array}{c}
\tilde{x}_{i} \\
\tilde{y}_{i} \\
\tilde{z}_{i}
\end{array}\right)=\left(\begin{array}{c}
x_{i 0} \\
y_{i 0} \\
z_{i 0}
\end{array}\right)+\left(\begin{array}{c}
\tau x_{i} \\
\tau y_{i} \\
\tau z_{i}
\end{array}\right),
$$

$\operatorname{arba} \tilde{\boldsymbol{T}}_{\boldsymbol{i}}=\boldsymbol{T}_{\boldsymbol{i} 0}+\boldsymbol{\tau}$, čia $\tilde{\boldsymbol{T}}_{i}=\left(\tilde{x}_{i}, \tilde{y}_{i}, \tilde{z}_{i}\right)^{T}$.

Išlygintujų $i$-tojo taško koordinačių vektoriaus $\tilde{\boldsymbol{T}}_{\boldsymbol{i}}$ kovariacijų matrica $\boldsymbol{K}_{\tilde{T}_{i}}$ yra lygi

$$
\boldsymbol{K}_{\tilde{\boldsymbol{T}}_{i}}=\boldsymbol{K}_{\boldsymbol{T}_{i 0}}+\boldsymbol{K}_{\tau}=\boldsymbol{K}_{\tau},
$$

nes $\boldsymbol{K}_{\boldsymbol{T}_{\boldsymbol{i} 0}}=0$, kai išlyginimo procedūrose fiksuotas nekintantis taško apytikrių koordinačių vektorius.

Diferencijavę matricas [2, 4] pagal formulę (4) gauname

$$
\begin{aligned}
& \boldsymbol{K}_{\tau}=\left(\frac{\partial \boldsymbol{\tau}}{\partial \boldsymbol{L}}\right)_{0} \boldsymbol{K}_{\boldsymbol{L}}\left(\frac{\partial \boldsymbol{\tau}}{\partial \boldsymbol{L}}\right)_{0}^{\boldsymbol{T}}+\left(\frac{\partial \tau}{\partial \boldsymbol{A}}\right)_{0} \boldsymbol{K}_{\boldsymbol{A}}\left(\frac{\partial \boldsymbol{\tau}}{\partial \boldsymbol{A}}\right)_{0}^{\boldsymbol{T}}= \\
& \boldsymbol{K}_{\tau(\boldsymbol{L})}+\boldsymbol{K}_{\tau(\boldsymbol{a})},
\end{aligned}
$$

čia dalinès išvestinès simbolio indeksas 0 rodo, kad jos reikšmé apskaičiuota pagal žinomas atitinkamų dydžių reikšmes.

Toliau gauname formulès (5) komponentę $\boldsymbol{K}_{\tau(\boldsymbol{L})}$ esant linijų ilgių matavimo klaidoms:

$$
\begin{aligned}
& \boldsymbol{K}_{\tau(L)}=\left(\boldsymbol{N}^{-1} \boldsymbol{A}^{\boldsymbol{T}} \boldsymbol{P}\right) \boldsymbol{K}_{L}\left(\boldsymbol{N}^{-1} \boldsymbol{A}^{\boldsymbol{T} P}\right)^{\boldsymbol{T}}= \\
& \boldsymbol{N}^{-1} \boldsymbol{A}^{\boldsymbol{T}} \boldsymbol{P} \boldsymbol{K}_{S} \boldsymbol{P A N ^ { - 1 }}=\sigma_{0}^{2} \boldsymbol{N}^{-1},
\end{aligned}
$$

čia $\boldsymbol{K}_{\boldsymbol{S}}=\boldsymbol{K}_{\boldsymbol{S}, 0}+\boldsymbol{K}_{\boldsymbol{S}}=\boldsymbol{K}_{\boldsymbol{S}}=\sigma_{0}^{2} \boldsymbol{P}^{-1}, \quad \sigma_{0}-$ išmatuoto linijos ilgio, kai svoris lygus vienetui, standartinis nuokrypis.

Kovariaciju matricos $\boldsymbol{K}_{\tau}$ komponente் $\boldsymbol{K}_{\tau(\boldsymbol{L})}$ rodo išmatuotų linijų ilgių klaidų įtaką vektoriaus $\tau$ nustatymo tikslumui.

Antroji kovariacijų matricos $\boldsymbol{K}_{\tau}$ komponente $\boldsymbol{K}_{\tau(\boldsymbol{a})}$ rodo pataisų lygčių koeficientų klaidų itaką vektoriaus $\tau$ nustatymo tikslumui. $\boldsymbol{K}_{\tau(\boldsymbol{a})}$ skaičiavimuose vektoriaus $\boldsymbol{\tau}$ skleistinę panaudosime kitu pavidalu:

$$
\begin{gathered}
\tau=-N^{-1} A^{T} P L=-N^{-1} L_{p n}^{T} A_{n}= \\
-N^{-1}\left(\begin{array}{ccc}
L_{p}^{T} & & \\
& L_{p}^{T} & \\
& & L_{p}^{T}
\end{array}\right)\left(\begin{array}{l}
A_{1} \\
A_{2} \\
A_{3}
\end{array}\right),
\end{gathered}
$$

čia $\boldsymbol{L}_{\boldsymbol{p}}=\boldsymbol{P L}, \quad \boldsymbol{A}_{\boldsymbol{i}}$ - matricos $\boldsymbol{A} i$-tasis stulpelis ( $i$-tasis vektorius), $i=1,2,3$.

Formulejje (7) taikomi žymèjimai

$$
A^{T}=\left(\begin{array}{c}
A_{1}^{T} \\
A_{2}^{T} \\
A_{3}^{T}
\end{array}\right), \quad L_{p}=P L=\left(\begin{array}{c}
p_{1} l_{1} \\
p_{2} l_{2} \\
\ldots \\
p_{n} l_{n}
\end{array}\right)
$$

ir $A^{T} P L=L_{p n}^{T} A_{n}, L_{p n}=\left(L_{p} L_{p} L_{p}\right)_{\mathrm{diag}}$.

Kovariaciju matricos $\boldsymbol{K}_{\tau}$ komponentę $\boldsymbol{K}_{\tau(\boldsymbol{a})}$, taikydami lygybę (7), gauname:

$$
\begin{aligned}
& K_{\tau(a)}=N^{-1} L_{p n}^{T} K_{A_{n}}\left(N^{-1} L_{p n}^{T}\right)^{T}= \\
& N^{-1} L_{p n}^{T} K_{A_{n}} L_{p n} N^{-1}
\end{aligned}
$$


Pataisų lygčiu koeficientų kovariacijų matricos $\boldsymbol{K}_{\boldsymbol{A}_{n}}$ išraiška:

$$
K_{A_{n}}=\left(\begin{array}{lll}
\boldsymbol{K}_{A_{1} A_{1}} & \boldsymbol{K}_{A_{1} A_{2}} & \boldsymbol{K}_{A_{1} A_{3}} \\
\boldsymbol{K}_{A_{2} A_{1}} & \boldsymbol{K}_{A_{2} A_{2}} & \boldsymbol{K}_{A_{2} A_{3}} \\
K_{A_{3} A_{1}} & \boldsymbol{K}_{A_{3} A_{2}} & \boldsymbol{K}_{A_{3} A_{3}}
\end{array}\right),
$$

čia $\boldsymbol{K}_{\boldsymbol{A}_{i} \boldsymbol{A}_{j}}-\boldsymbol{A}_{\boldsymbol{i}}$-tojo ir $\boldsymbol{A}_{j}$-tojo matricos $\boldsymbol{A}$ stulpelių kovariaciju matrica, kurios matmenys $(n \times n) . \quad \boldsymbol{A}_{1}$ stulpelio elementams apskaičiuoti taikomi linijų ilgių koordinačiu prieaugiai $\Delta x, \boldsymbol{A}_{2}$ stulpelio elementams $\Delta y$ ir $\boldsymbol{A}_{3}$ stulpelio elementams $-\Delta z$.

Kovariacijų matricos, pavyzdžiui $K_{A_{1} A_{1}}, \quad K_{A_{1} A_{3}}$ rašomos taip:

$$
\begin{aligned}
& \boldsymbol{K}_{A_{1} A_{1}}=\left(\begin{array}{cccc}
K\left(a_{11}, a_{11}\right) & K\left(a_{11}, a_{21}\right) & \ldots & K\left(a_{11}, a_{n 1}\right) \\
K\left(a_{21}, a_{11}\right) & K\left(a_{21}, a_{21}\right) & \ldots & K\left(a_{21}, a_{n 1}\right) \\
\ldots & & \ldots & \\
K\left(a_{n 1}, a_{11}\right) & K\left(a_{n 1}, a_{21}\right) & \ldots & K\left(a_{n 1}, a_{n 1}\right)
\end{array}\right),(10 \\
& \boldsymbol{K}_{A_{1} A_{3}}=\left(\begin{array}{cccc}
K\left(a_{11}, a_{13}\right) & K\left(a_{11}, a_{23}\right) & \ldots & K\left(a_{11}, a_{n 3}\right) \\
K\left(a_{21}, a_{13}\right) & K\left(a_{21}, a_{23}\right) & \ldots & K\left(a_{21}, a_{n 3}\right) \\
\ldots & & \ldots & \\
K\left(a_{n 1}, a_{13}\right) & K\left(a_{n 1}, a_{23}\right) & \ldots & K\left(a_{n 1}, a_{n 3}\right)
\end{array}\right) .
\end{aligned}
$$

Analogiškai skaičiuojamos ir kitos kovariaciju matricos $\boldsymbol{K}_{\boldsymbol{A}_{n}}$ (9) komponentès. Kadangi linijų ilgiai matuojami nepriklausomai vienas nuo kito, tai formulès (9) komponentès $\boldsymbol{K}_{A_{1} A_{1}}, \boldsymbol{K}_{A_{1} A_{2}}, \ldots$ ir kt. turès tik diagonaliuosius narius, kurie yra atitinkamų pataisu lygčių koeficientų kovariacijos. Kai kurių kovariacijų išraiškos:

$$
\begin{aligned}
& K\left(a_{11}, a_{11}\right)=M\left(\frac{1}{S_{1 i}} \delta \Delta x_{1 i} \cdot \frac{1}{S_{1 i}} \delta \Delta x_{1 i}\right)= \\
& \frac{1}{S_{1 i}^{2}} D \Delta x_{1 i}, \\
& K\left(a_{11}, a_{12}\right)=M\left(\frac{1}{S_{1 i}} \delta \Delta x_{1 i} \cdot \frac{1}{S_{1 i}} \delta \Delta y_{1 i}\right)= \\
& \frac{1}{S_{1 i}^{2}} K\left(\Delta x_{1 i}, \Delta y_{1 i}\right), \\
& K\left(a_{11}, a_{13}\right)=M\left(\frac{1}{S_{1 i}} \delta \Delta x_{1 i} \cdot \frac{1}{S_{1 i}} \delta \Delta z_{1 i}\right)= \\
& \frac{1}{S_{1 i}^{2}} K\left(\Delta x_{1 i}, \Delta z_{1 i}\right),
\end{aligned}
$$

čia $\delta \Delta x_{1 i}=\Delta x_{1 i}-M \Delta x_{1 i}, \quad M \Delta x_{1 i}-$ koordinačių prieaugio $\Delta x_{1 i}$ vidurkis, $D \Delta x_{1 i}-$ koordinačiu prieaugio $\Delta x_{1 i}$ dispersija. Analogiškos ir $\delta \Delta y_{1 i}, \delta \Delta z_{1 i}$ dydžių išraiškos.
Atitinkamų dydžiu kovariacijos nèra didesnès nei pavienių dydžių dispersijos, t. y.:

$$
\begin{aligned}
& K\left(\Delta x_{1 i}, \Delta y_{1 i}\right) \leq D \Delta x_{1 i}, \\
& K\left(\Delta x_{1 i}, \Delta y_{1 i}\right) \leq D \Delta y_{1 i} .
\end{aligned}
$$

ir atitinkamos kitų dydžių nelygybès.

Nustatysime pavienio taško koordinačių pataisų vektoriaus $\boldsymbol{\tau}$ kovariaciju matricą $\boldsymbol{K}_{\tau(\boldsymbol{a})}$, esant pataisu lygčiu koeficientų klaidų itakai, paprastame pavyzdyje, kai $n=4, \quad S_{j i} \approx 100 \mathrm{~m}, \quad j=(1,2,3,4), \quad D \Delta x_{1 i} \approx$ $D \Delta y_{1 i} \approx D \Delta z_{1 i} \approx \ldots \approx 1 \mathrm{~m} \quad$ (parametrinių lygčių linearizavimo tikslumas), $a_{n 1} \approx a_{n 2} \approx a_{n 2}<1, \quad P=E$, $L=(1111)^{T} \mathrm{~m}, \sigma_{0}=0,01 \mathrm{~m}$.

Taikydami formules (8-12) apskaičiuojame vidutinę reikšmę:

$$
K_{\tau(a)} \leq 4 \cdot 10^{-4} N^{-1} N^{-1} \approx 0,25 \cdot 10^{-4} E m^{2},
$$

kai $N^{-1} \approx 0,25 E$.

Taigi pavienio taško koordinačių pataisu $\tau x, \tau y, \tau z$ bei išlygintuju koordinačių standartinių nuokrypių reikšmės dèl pataisų lygčių koeficientų klaidų itakos yra lygios $\sigma_{\tilde{x}(a)} \approx \sigma_{\tilde{y}(a)} \approx \sigma_{\tilde{z}(a)} \leq 0,005 \mathrm{~m}$.

Koordinačiu pataisu $\tau x, \tau y, \tau z$ bei išlygintuju koordinačių standartinių nuokrypių reikšmès dėl linijų ilgių matavimo klaidų yra lygios:

$$
\sigma_{\tilde{x}(l)} \approx \sigma_{\tilde{y}(l)} \approx \sigma_{\tilde{z}(l)} \leq \sigma_{0} \sqrt{\left(N^{-1}\right)_{i i}} 0,005 \mathrm{~m} .
$$

\section{Išlygintųjų linijų ilgių tikslumo įvertinimas}

Itvertinsime išlygintujų linijų ilgių vektoriaus $\tilde{\boldsymbol{S}}$ tikslumą, atsižvelgdami i parametrinių pataisų lygčių koeficientu $a_{i j}$ klaidų itaką. Galima parašyti

$$
\tilde{S}=S+v=S_{0}+A \tau,
$$

arba

$$
\tilde{S}=S_{0}+\left(\begin{array}{c}
A_{e 1} \\
A_{e 2} \\
\vdots \\
A_{e n}
\end{array}\right) \tau
$$

čia $\boldsymbol{A}_{\boldsymbol{e} i}$ - matricos $\boldsymbol{A} \boldsymbol{i}$-toji eilutè.

Lygybę (15) išreikšime kitu pavidalu -

$$
\tilde{S}=S_{0}+\tau_{e}^{T} A_{e}=S_{0}+\left(\begin{array}{cccc}
\tau^{T} & & & 0 \\
& \tau^{T} & & \\
& & \ddots & \\
0 & & & \tau^{T}
\end{array}\right)\left(\begin{array}{c}
A_{e 1}^{T} \\
A_{e 2}^{T} \\
\vdots \\
A_{e n}^{T}
\end{array}\right)
$$


Turint naujų išlygintujų linijų ilgių vektoriaus $\tilde{\boldsymbol{S}}$ pavidalą (16) galima parašyti kovariaciju matricos išraišką esant pataisų lygčių koeficientų klaidų ittakai:

$$
K_{\tilde{S}(a)}=K_{S_{0}}+\tau_{e}^{T} K_{A e} \tau_{e}
$$

čia $\tau_{e}=(\tau, \tau, \ldots, \tau)_{\text {diag }}, \quad K_{A_{e}}-$ matricos $A$ eilučiu tarpusavio kovariacijų matrica,

$$
K_{A_{e}}=\left(\begin{array}{cccc}
K_{A_{e 1} A_{e 1}} & K_{A_{e 1} A_{e 2}} & \ldots & K_{A_{e 1} A_{e n}} \\
K_{A_{e 2} A_{e 1}} & K_{A_{e 2} A_{e 2}} & \ldots & K_{A_{e 2} A_{e n}} \\
\ldots & \ldots & \ldots & \ldots \\
K_{A_{e n} A_{e 1}} & K_{A_{e n} A_{e 2}} & \ldots & K_{A_{e n} A_{e n}}
\end{array}\right) .
$$

Kadangi linijų ilgiai matuojami nepriklausomai vienas nuo kito, tai kovariacijuc matricos $\boldsymbol{K}_{A_{e}}$ nediagonalieji nariai yra lygūs nuliui. Taigi lygybè (17) igauna ši pavidalą:

$$
\begin{gathered}
\boldsymbol{K}_{\tilde{\boldsymbol{S}}(\boldsymbol{a})}=\boldsymbol{K}_{S_{0}}+ \\
\left(\begin{array}{cccc}
\boldsymbol{\tau}^{T} \boldsymbol{K}_{A_{e 1} A_{e 1}} \boldsymbol{\tau} & & & \\
& \tau^{T} \boldsymbol{K}_{A_{e 2} A_{e 2}} \boldsymbol{\tau} & & \\
& & \ddots & \\
0 & & & \boldsymbol{\tau}^{T} \boldsymbol{K}_{A_{e n} A_{e n}} \boldsymbol{\tau}
\end{array}\right),
\end{gathered}
$$

čia $\boldsymbol{K}_{\boldsymbol{S}_{0}}=0$, nes išlyginimo procedūrose $\boldsymbol{S}_{0}$ laikomas nekintamu fiksuotu vektoriumi.

Matricos $\boldsymbol{A} n$-tosios eilutès narių tarpusavio kovariacijų matrica tokia:

$$
\begin{aligned}
& \boldsymbol{K}_{A_{e n} A_{e n}}= \\
& \left(\begin{array}{lll}
K\left(a_{n 1}, a_{n 1}\right) & K\left(a_{n 1}, a_{n 2}\right) & K\left(a_{n 1}, a_{n 3}\right) \\
K\left(a_{n 2}, a_{n 1}\right) & K\left(a_{n 2}, a_{n 2}\right) & K\left(a_{n 2}, a_{n 3}\right) \\
K\left(a_{n 3}, a_{n 1}\right) & K\left(a_{n 3}, a_{n 2}\right) & K\left(a_{n 3}, a_{n 3}\right)
\end{array}\right) .
\end{aligned}
$$

Kai kurių kovariacijų išraiškos -

$$
\begin{aligned}
& K\left(a_{n 1}, a_{n 1}\right)=M\left(\frac{1}{S_{n i}} \delta \Delta x_{n i} \cdot \frac{1}{S_{n i}} \delta \Delta x_{n i}\right)= \\
& \frac{1}{S_{n i}^{2}} D \Delta x_{n i}, \\
& K\left(a_{n 1}, a_{n 2}\right)=M\left(\frac{1}{S_{n i}} \delta \Delta x_{n i} \cdot \frac{1}{S_{n i}} \delta \Delta y_{n i}\right)= \\
& \frac{1}{S_{n i}^{2}} K\left(\Delta x_{n i}, \Delta y_{n i}\right), \\
& K\left(a_{n 1}, a_{n 3}\right)=M\left(\frac{1}{S_{n i}} \delta \Delta x_{n i} \cdot \frac{1}{S_{n i}} \delta \Delta z_{n i}\right)= \\
& \frac{1}{S_{n i}^{2}} K\left(\Delta x_{n i}, \Delta z_{n i}\right) .
\end{aligned}
$$

Taikydami ankstesniame pavyzdyje pateiktu pradinių duomenų reikšmes gauname:

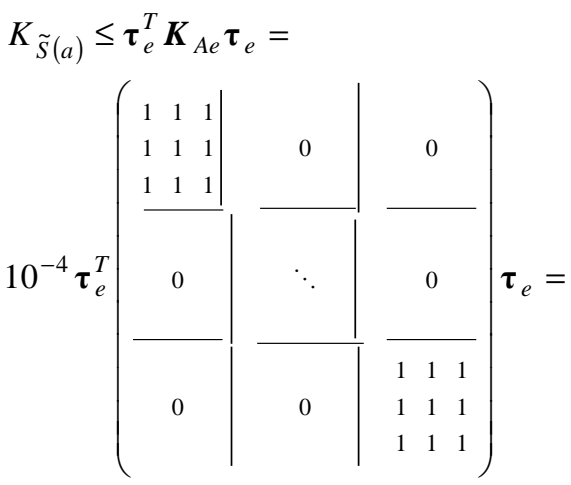

$10^{-4} \cdot 9 \cdot \boldsymbol{E}$

kai $\boldsymbol{\tau}=\left(\begin{array}{lll}1 & 1 & 1\end{array}\right)^{T} m$.

Taigi šiuo atveju išlygintujų linijų ilgių $\tilde{S}_{n i}$ trilateracijos tinkle tikslumas esant pataisų lygčių koeficientų klaidų itakai įvertinamas ribine standartinio nuokrypio reikšme $\sigma_{\tilde{S}_{n i(a)}}<0,03 \mathrm{~m}$.

Išlygintujų linijų ilgių vektoriaus $\tilde{\boldsymbol{S}}$ tikslumas, atsižvelgiant ì linijų ilgių matavimo klaidas, įvertinamas kovariacijų matrica $\boldsymbol{K}_{\tilde{S}(l)}$, kuri lygi

$$
K_{\tilde{S}(l)}=\sigma_{0}^{2} A N^{-1} A^{T} .
$$

Panaudoję ankstesnio pavyzdžio pradinius duomenis turime

$$
\begin{aligned}
& \boldsymbol{K}_{\tilde{\boldsymbol{S}}(l)} \leq 10^{-4} \cdot 0,25 \boldsymbol{E}\left(\begin{array}{ccc}
1 & 1 & 1 \\
. & . & . \\
1 & 1 & 1
\end{array}\right)\left(\begin{array}{ccc}
1 & \ldots & 1 \\
1 & \ldots & 1 \\
1 & \ldots & 1
\end{array}\right)= \\
& 0,25 \cdot 10^{-4} \cdot 3\left(\begin{array}{cccc}
1 & 1 & \ldots & 1 \\
1 & 1 & \ldots & 1 \\
. & . & \ldots & . \\
1 & 1 & \ldots & 1
\end{array}\right)
\end{aligned}
$$

Išlygintojo linijos ilgio vidutinè standartinio nuokrypio dẻl linijų ilgių matavimo klaidų reikšmė $\sigma_{\tilde{S}_{n i(a)}}$ apibrèžiama nelygybe $\sigma_{\tilde{S}_{n i(a)}} \leq 0,008 \mathrm{~m}$.

\section{Išvados}

1. Pasiūlytas daugkartine linijine sankirta nustatomų taškų erdvinių koordinačių skaičiavimo, taikant linearizuotų parametrinių lygčių sistemą, metodas. Parametrinių pataisų lygčių sistema sprendžiama mažiausiujų kvadratų metodu.

2. Išlygintujų erdvinių koordinačių tikslumui ivvertinti išvestos jų kovariacijų formulès (5), (6), (8). Išlygintujų koordinačių kovariacijų matricą sudaro dvi 
komponentės. Viena kovariacijų komponentė i̇vertina išmatuotų linijų ilgių klaidų itaką erdvinių koordinačių klaidoms, o antroji - parametrinių pataisu lygčiuc koeficientų klaidų itaką išlygintujų koordinačių klaidoms.

\section{Literatūra}

1. Koch, K.-R. Räumliche Helmert-Transformation variabler Koordinaten im Gauss-Helmert und im Gauss-Markoff Modell. Z. f. Vermessungswessen, No 3. Stuttgart: Verlag K. Witwer, 2002, S. 147-152.

2. Koch, K.-R. Einführung in die Bayes-Statistik. Berlin Heidelberg: Springer-Verlag, 2000. 225 S.

3. Markuze, J. I. Fundamentals of adjustments computations (Основы уравнительных вычислений). Moscow: Nedra, 1990. 240 p. (in Russian).

4. Skeivalas, J. Treatment of correlated geodetic measurements (Koreliuotu geodezinių matavimu rezultatu matematinis apdorojimas). Vilnius: Technika, 1995. 272 p. (in Lithuanian).

5. Fischer, B.; Hegland, M. Collocation, Filtering and Nonparametric Regression, Part 1. Z. f. Vermessungswessen, No 1. Stuttgart: Verlag K. Witwer, 1999, S. 17-24.
6. Chitau, D. Über Koordinatentransformation in dreidimensionalen Systemen mit linearen Modellen. $Z . \quad f$. Vermessungswessen, No 5. Stuttgart: Verlag K. Witwer, 1996, S. 203-211.

7. Hirsch, J.; Wendt, K. Calibration of Grid Plates by MultiLateration (ISI) In: Proceedings of $8^{\text {th }}$ International Symposium on Measurement and Quality Control in Production, Erlangen, Oct 12-15, 2004, p. 663-668.

Jonas SKEIVALAS. Prof, Doctor Habil.

Vilnius Gediminas Technical University. Dept of Geodesy and Cadastre, Saulètekio al. 11, LT-10223 Vilnius, Lithuania $(\mathrm{Ph}+3705274$ 4703, Fax +370 5274 4705),

e-mail: jonas.skeivalas@ap.vtu.lt.

Author of two monographs and more than 130 scientific papers. Participated in many intern conferences and research visits to the Finish Geodetic Institute.

Research interests: processing of measurements with respect to tolerances, adjustment of geodetic networks.

Robertas DARGIS. Director, UAB „Eika“, A. Goštauto g. 40A, LT-01112 Vilnius, Lietuva.

Dipl. Eng. (1984). President of the Lithuanian association of real estate developers.

Research interests: engineering geodesy, adjustment of geodetic networks. 